\title{
ERRATUM
}

\section{Water-Maze Learning in the Mouse Correlates with Variation in Hippocampal Morphology}

\author{
H. Schwegler, ${ }^{1}$ W. E. Crusio, ${ }^{1}$ H.-P. Lipp, ${ }^{2}$ and B. Heimrich ${ }^{1}$
}

The following reference was omitted from the above-titled paper published in 1988 [Behav. Genet. 18:153-165 (1988)]. Lichter (1983) should have been cited in the text of the article at the very end of the Introduction section as follows: ". . . hypotheses only (Lichter, 1983)."

In the reference section, it should have appeared: Lichter, P. (1983). Feinanalyse von orientierungsabhängigem Lernverhalten im Water-Maze bei Mäuse-Inzuchtstämmen, Diplomarbeit, University of Heidelberg.

'Institut für Humangenetik und Anthropologie, Universität Heidelberg, Im Neuenheimer Feld 328, 6900 Heidelberg, F.R.G.

${ }^{2}$ Anatomisches Institut, Winterthurer Strasse 190, 8057 Zürich, Switzerland. 